\title{
Use of ibuprofen sustained release for treating osteoarthritic pain: findings from I5 general medical practices in Egypt
}

This article was published in the following Dove Press journal:

Open Access Rheumatology: Research and Reviews

12 May 2014

Number of times this article has been viewed

\author{
Nabil Khalifa' \\ Timour El-Husseini' \\ Ahmed Morrah ${ }^{2}$ \\ Elshenawy Mostafa ${ }^{3}$ \\ Hesham Hamoud ${ }^{4}$ \\ 'Department of Orthopedic Surgery, \\ Ain Shams University, Cairo, Egypt; \\ ${ }^{2}$ Department of Orthopedic Surgery, \\ Cairo University, Cairo, Egypt; \\ ${ }^{3}$ Department of Orthopedic Surgery, \\ Mansoura University, Mansoura, Egypt; \\ ${ }^{4}$ Department of Rheumatology, Azhar \\ University, Cairo, Egypt
}

Purpose: Ibuprofen sustained release (SR) has been shown to provide effective symptomatic pain relief in chronic arthritic conditions such as osteoarthritis in European and US patient populations. Few studies have been conducted in other patient populations. A 4-week prospective multicenter open-label observational study was designed to explore and describe the combined effect of ibuprofen SR and standard medical care in patients suffering from osteoarthritis in 15 general medical practices in Egypt.

Patients and methods: In total, 519 patients were prescribed ibuprofen SR $2 \times 800 \mathrm{mg}$ once daily for 4 weeks.

Results: Ibuprofen SR combined with standard medical care significantly improved day and night pain, with $99.4 \%$ of the patients reporting improvement. The treatment reduced the symptom severity of joint tenderness/stiffness and the duration of morning stiffness, and allowed more patients to carry out normal activities. Overall compliance with the prescribed ibuprofen SR regimen was $98.6 \%$. Ibuprofen SR was generally well tolerated with no serious adverse events reported during the study. There was no increase in blood pressure or heart rate.

Conclusion: The combined treatment provided effective relief of pain in patients with osteoarthritis in a large real-life general medical practice setting in Egypt. Owing to its convenient once-daily dosing regimen, ibuprofen SR may enhance patient compliance.

Keywords: chronic arthritis, compliance, pain score, real-life

\section{Introduction}

Osteoarthritis is a leading cause of functional disability characterized by pain, stiffness, joint deformity, and restricted mobility. Its prevalence varies widely and limited data are available from developing countries. The World Health Organization/International League of Associations for Rheumatology Community Oriented Program for Control of Rheumatic Diseases (WHO-ILAR COPCORD) reported the prevalence of symptomatic osteoarthritis of the knee as $8.5 \%$ in a rural Egyptian population. ${ }^{1}$ Extrapolation of these data, and of evidence from the United States indicating that up to $13.9 \%$ of adults may have signs and symptoms of osteoarthritis, suggest that there may be millions of people with osteoarthritis among the 82.5 million population of Egypt. ${ }^{2,3}$

It has been estimated that the burden of disability from musculoskeletal disorders in developing countries is 2.5 times that of the developed world, amounting to 21,076,000 disability-adjusted life years. ${ }^{1}$ In the WHO-ILAR COPCORD study, $16.2 \%$ of the rural Egyptian population reported pain; $9.1 \%$ of those reported knee pain and $1.8 \%$ reported hand pain. ${ }^{1}$ Osteoarthritis has been identified as a noncommunicable disease that should be targeted by the Egyptian health care system. ${ }^{4}$
Ain Shams University, Department of Orthopedic Surgery, Faculty of Medicine, Khalida El-Maamon Street, Abbasiya Square, Cairo, II566, Egypt

Tel +20 I22 2133334

$\mathrm{Fax}+201224557878$

Email nkhalifa44@gmail.com 
Short-term treatment with nonsteroidal anti-inflammatory drugs (NSAIDs) can reduce pain and improve quality of life, and can decrease levels of proinflammatory cytokines in synovial fluid, which are known to contribute to the inflammation and joint damage observed in patients with osteoarthritis. ${ }^{5}$ All brands of NSAIDs are available to purchase without a prescription in Egypt, and self-prescription and administration are widespread. While physicians treating osteoarthritis do not encourage this practice, it is particularly important to acknowledge this overuse/misuse and to recommend efficacious drugs with a proven safety profile.

Ibuprofen is well-established as an effective and one of the best-tolerated NSAIDs available for the management of pain due to osteoarthritis. ${ }^{6-11}$ It demonstrates a dose-dependent diffusion in both plasma and synovial fluid, which is related to reductions in pain intensity and an improvement in health status. ${ }^{12}$ The conventional release formulation of ibuprofen is rapidly absorbed and has a relatively short elimination half-life of about 2 hours. Therefore, it should be taken three or four times a day to achieve and maintain therapeutically effective plasma concentrations over 24 hours. ${ }^{5,13}$ This dosing frequency may reduce treatment compliance and, therefore, overall efficacy. ${ }^{14}$ In real-life clinical practice, compliance with medications that have less frequent dosing is typically higher than those with more frequent dosing. ${ }^{15}$

A sustained-release (SR) formulation of ibuprofen (Brufen Retard $^{\circledR}$; Abbott Laboratories, Abbott Park, IL, USA) has been developed that allows once-daily dosing of $1,600 \mathrm{mg}$ (two tablets of $800 \mathrm{mg}$ ) and delivers well-controlled therapeutically effective plasma concentrations over 24 hours..$^{13}$ Ibuprofen SR has been demonstrated to have high rates of compliance ${ }^{14}$ and to improve pain, joint tenderness, joint stiffness, as well as other symptoms of osteoarthritis, rheumatoid arthritis, and other musculoskeletal conditions, during both day and night. Its tolerability is comparable to that of conventional-release ibuprofen. ${ }^{14,16-26}$

The majority of the studies were largely conducted in European and North American populations. Limited data are available from real-life clinical practice in developing countries and mixed ethnic populations regarding the use of ibuprofen SR for treating osteoarthritic pain. Racial and ethnic differences in the prevalence, outcomes, and care of patients with osteoarthritis have been observed. ${ }^{27}$ The aim of the study was to explore and describe the combined effect of ibuprofen SR and standard medical care in patients suffering from osteoarthritis in general medical practices in Egypt.

\section{Material and methods}

This was an open-label prospective multicenter observational study conducted at 15 general medical practices in Egypt between June 2010 and November 2010. The study protocol was submitted to and approved by relevant institutional review boards, local regulators, and clinical research and scientific ethical committees of the participating centers. All investigators were trained in Good Clinical Practice as outlined in the Guidelines for Good Clinical Practice issued by the International Conference on Harmonization of Technical Requirements for Registration of Pharmaceuticals for Human Use (the ICH-GCP guidelines). ${ }^{28}$ Patients provided written informed consent before being enrolled in the study.

Patients aged 18 years or over with clinical or radiological evidence of osteoarthritis who sought treatment were eligible for inclusion. The main exclusion criteria were: history of hypersensitivity to ibuprofen or other NSAIDs; active cardiovascular disease and use of aspirin or warfarin as prophylaxis for myocardial infarction or stroke; moderate-to-severe renal or hepatic impairment; active peptic ulcer; Crohn's disease; and pregnancy.

Patients receiving NSAIDs were asked to undertake a washout period of up to 10 days, depending on the half-life of the drug. Patients were prescribed ibuprofen SR at a dose of two $800 \mathrm{mg}$ tablets once daily for 4 weeks at the discretion of the investigator as a part of the center's standard medical care (ie, not according to any prespecified criteria in the study protocol). Patients were permitted to use other drugs to treat comorbidities, except those with known contraindications as detailed in the ibuprofen SR (Brufen Retard ${ }^{\circledR}$ ) product license. No additional procedures, other than the standard care, were provided.

\section{Study assessments}

Patients visited the general medical practice four times; at baseline, after 2 and 4 weeks (week 2 and week 4, respectively), and at a follow-up visit 2 weeks after stopping treatment. If treatment was discontinued before the end of week 4 , or if treatment was continued for longer than 4 weeks, the reason was recorded.

The primary outcome measure was the mean change in day and night pain score between baseline and week 4. Day and night pain during the past 24 hours was assessed by the patient on a $0-8$ numeric pain scale, with 0 representing no pain and 8 very severe pain, similar to a scale used in previous studies. ${ }^{14,19}$

Secondary outcome measures included scoring of symptom severity of joint tenderness/stiffness, the duration 
of morning stiffness, and the ability to carry out normal activities. Joint tenderness/stiffness symptom severity was measured on a 4 -point scale where $0=$ none, $1=$ mild, $2=$ moderate, and $3=$ severe, as used in other studies. ${ }^{14,19}$ The ability to carry out normal activity was assessed by asking the patient a simple yes/no question: "Can you perform your normal daily activities?"

In addition, at weeks 2 and 4, patients were asked if they had forgotten to take any of their treatment, changed the dose or administration, or discontinued the treatment since their last visit. The maximum number of tablets that should have been taken during each 2-week interval was 28 .

\section{Safety and tolerability}

An adverse event (AE) was defined as any untoward medical occurrence in a patient, regardless of whether it was considered to be causally related to the use of treatment. All AEs, including symptoms, signs, and diseases, reported during the study and outcomes were recorded by investigators. Event severity (mild AEs were transient and easily tolerated, moderate AEs caused discomfort and interrupted usual activities, severe AEs caused considerable interference with usual activities and may have been incapacitating or life-threatening) and relationship to ibuprofen SR (probably related, possibly related, probably not related, or not related) were determined and recorded by the investigator. At each visit, patients underwent a physical examination and vital signs, including blood pressure and heart rate, were monitored.

\section{Statistical analysis}

Compliance with the ibuprofen SR regimen was calculated as the dose actually taken divided by the prescribed dose $\times 100$.

Mean changes from baseline in the day and night pain score were tested for statistical significance using the paired $t$-test. Changes from baseline were classified as improved (ie, a reduction in pain score), no change (ie, no change in pain score), or worsened (ie, an increase in pain score). Joint tenderness/stiffness symptom severity scores were compared between week 2 and baseline, and week 4 and baseline, using Wilcoxon signed-rank test. For this outcome also, the changes from baseline were classified as improved, no change, or worsened.

All $P$-values were two-sided, and $P$-values $<0.05$ were considered significant. As per protocol, this observational real-life study was not powered for any of the specified assessments.

\section{Results}

In total, 519 patients from 15 centers were enrolled in the study, with the number of patients per center varying from 29 to 40 . One patient withdrew from the study because of poor compliance (see Figure 1). All available data of the 519 patients were included in the statistical analyses.

The study enrolled 342 (65.9\%) Caucasian and 177 (34.1\%) African patients. There were more women (348 [67.1\%]) than men (171 [32.9\%]). Mean ( \pm standard deviation) age, weight, and height were $54.7( \pm 10.4$, range 23 to 82$)$ years, $167.1( \pm 10.1) \mathrm{cm}$ and $86.6( \pm 13.2)$ $\mathrm{kg}$, respectively. The mean body mass index (BMI) of $31.1 \mathrm{~kg} / \mathrm{m}^{2}$ suggests that many of the patients were either overweight $\left(\right.$ BMI $\left.>25 \mathrm{~kg} / \mathrm{m}^{2}\right)$ or obese $\left(\mathrm{BMI}>30 \mathrm{~kg} / \mathrm{m}^{2}\right)$. Based upon patients' medical history, the most common disorders/conditions were musculoskeletal (89 [17.2\%]), surgical (64 [12.3\%]), and cardiovascular (49 [9.4\%]). The most frequently used concomitant medications included antihypertensives and antidiabetic agents.

\section{Clinical outcomes}

\section{Primary outcome}

The mean day and night pain score at baseline was $6.1( \pm 1.4)$ (see Table 1). After 4 weeks of treatment, the mean day and night pain score showed a statistically significant reduction to $2.1( \pm 1.7)(P<0.0001)$. At week 2 , the mean day and night pain score was $3.6( \pm 1.6)$; this reduction was also statistically significant $(P<0.0001)$. Almost all patients $(516 / 519$ [99.4\%]) reported improvement in pain at week 4 and none of the patients reported worsening of pain.

\section{Secondary outcomes}

At baseline, the majority of patients $(82.2 \%)$ reported moderate or severe joint tenderness/stiffness, while the remaining reported mild or no joint tenderness/stiffness (Table 2). At week 4, 50.5\% of the patients reported no joint

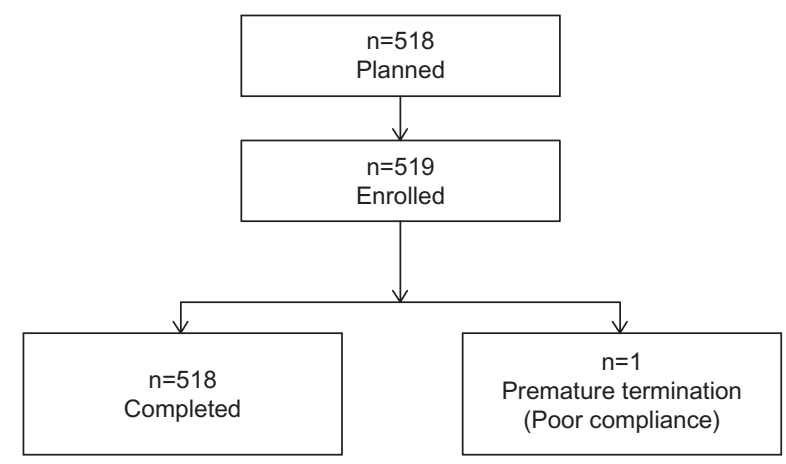

Figure I Patient disposition. 
Table I Day and night pain scores ${ }^{\mathrm{a}}$

\begin{tabular}{llll}
\hline & Baseline & Week 2 & Week 4 \\
\hline $\mathrm{N}$ & $5 \mathrm{I} 9$ & $5 \mathrm{I} 9$ & $5 \mathrm{I} 9$ \\
Pain score (mean $\pm \mathrm{SD})$ & $6.1 \pm \mathrm{I} .4$ & $3.6 \pm \mathrm{I} .6$ & $2.1 \pm \mathrm{I} .7$ \\
Mean change from baseline & & -2.5 & -4.0 \\
$\begin{array}{l}\text { P-value } \\
\text { Change from baseline, } \mathrm{n}(\%)\end{array}$ & $<0.000 \mathrm{I}$ & $<0.000 \mathrm{I}$ \\
$\quad$ Improved & & $50 \mathrm{I}(96.5)$ & $5 \mathrm{I} 6(99.4)$ \\
$\quad$ No change & & $\mathrm{I}(3.5)$ & $3(0.6)$ \\
Worsened & & $0(0)$ & $0(0)$ \\
\hline
\end{tabular}

Note: a Based on a $0-8$ numeric pain scale $(0=$ no pain, $8=$ very severe pain).

Abbreviation: SD, standard deviation.

tenderness/stiffness compared with $3.3 \%$ at baseline. The proportion of patients reporting severe joint tenderness/ stiffness was reduced from $32.0 \%$ at baseline to $0.6 \%$ at week 4. Both at weeks 2 and 4, the improvements in joint tenderness/stiffness were statistically significant $(P<0.0001)$. Overall, $91.1 \%$ of the patients were classified as having improved joint tenderness/stiffness at week 4 . No patients reported worsening of symptoms.

The duration of morning stiffness reduced during the study. The median (range) duration of morning stiffness was $20(0-120)$ minutes at baseline, $10(0-90)$ minutes at week 2, and 5 (0-90) minutes at week 4 . The proportion of patients reporting an $80 \%$ reduction in the duration of morning stiffness increased from $11.9 \%$ at week 2 to $44.0 \%$ at week 4 .

The proportion of patients who were able to carry out normal activities increased during the study from $33.1 \%$ at baseline to $73.4 \%$ at week 2 and $90.8 \%$ at week 4 (Figure 2).

\section{Compliance}

Compliance with the prescribed ibuprofen SR regimen was high throughout the study, with only a minor reduction from $99.4 \%$ after 2 weeks of treatment to $97.7 \%$ after 4 weeks of treatment. Overall compliance with the prescribed ibuprofen SR regimen was $98.6 \%$. The mean tablet consumption was

Table 2 Joint tenderness/stiffness symptom severity scores

\begin{tabular}{llll}
\hline & Baseline & Week 2 & Week 4 \\
\hline Score, $\mathrm{n}(\%)$ & & & \\
0 (none) & $17(3.3)$ & $87(16.8)$ & $262(50.5)$ \\
I (mild) & $75(14.5)$ & $271(52.2)$ & $210(40.5)$ \\
2 (moderate) & $261(50.3)$ & $156(30.1)$ & $44(8.5)$ \\
3 (severe) & $166(32.0)$ & $5(1.0)$ & $3(0.6)$ \\
$P$-value & & $<0.000 \mathrm{I}$ & $<0.000 \mathrm{I}$ \\
Change from baseline, $\mathrm{n}(\%)$ & & & \\
$\quad$ Improved & & $410(79.0)$ & $473(9 \mid . \mathrm{I})$ \\
$\quad$ No change & & $109(2 \mathrm{I} .0)$ & $46(8.9)$ \\
$\quad$ Worsened & & $0(0)$ & $0(0)$ \\
\hline
\end{tabular}

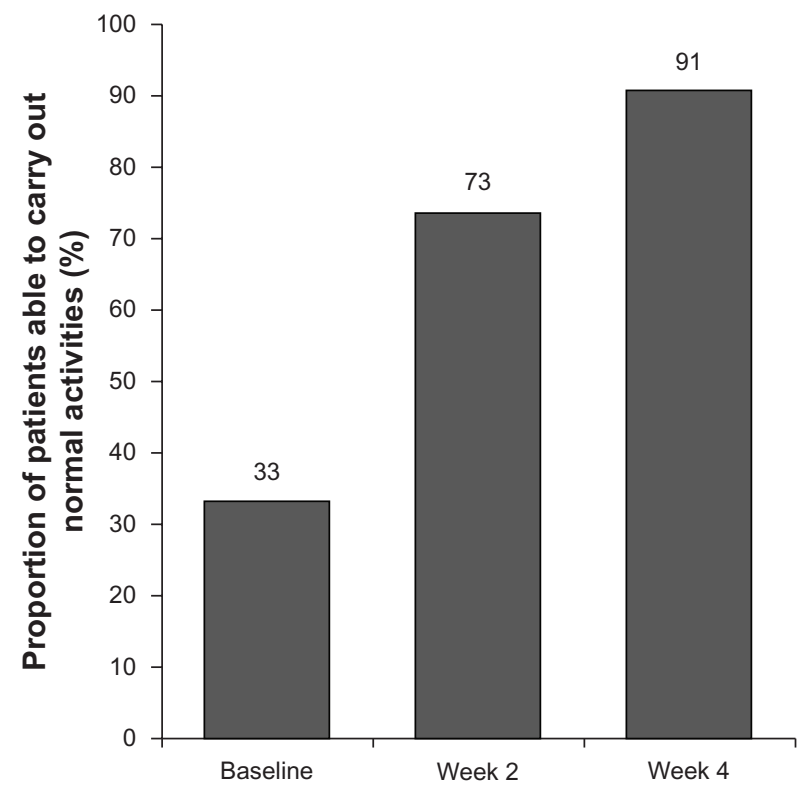

Figure 2 Ability to carry out normal activities before (baseline) and after 2 and 4 weeks of treatment.

$27.8( \pm 1.0)$ tablets at week 2 and $27.3( \pm 2.4)$ tablets at week 4.

\section{Safety and tolerability}

In total, 41 patients (7.9\%) reported 48 AEs (Table 3), of which 35 were considered by investigators to be possibly related to ibuprofen SR (ie, the AE had a strong temporal relationship to the study drug and an alternative etiology was equally or less likely). There were no unexpected AEs and the most commonly reported AEs were related to gastrointestinal disorders, particularly gastritis. All AEs were reported as being either mild $(n=38)$ or moderate $(n=10)$ in intensity. There were no serious AEs and no deaths or treatment discontinuations due to AEs.

Table 3 Adverse events in order of incidence

\begin{tabular}{ll}
\hline Adverse event & $\mathbf{n}(\%)$ \\
\hline Gastritis & $20(3.9)$ \\
Dyspepsia & $6(\mathrm{I} .2)$ \\
Nausea & $4(0.8)$ \\
Abdominal discomfort & $3(0.6)$ \\
Upper abdominal pain & $3(0.6)$ \\
Abdominal pain & $2(0.4)$ \\
Diarrhea & $2(0.4)$ \\
Reflux esophagitis & $2(0.4)$ \\
Headache & $2(0.4)$ \\
Gastrointestinal pain & $\mathrm{I}(0.2)$ \\
Vomiting & $\mathrm{I}(0.2)$ \\
Peripheral edema & $\mathrm{I}(0.2)$ \\
Pruritus & $\mathrm{I}(0.2)$ \\
\hline
\end{tabular}


Vital signs (blood pressure and heart rate) generally remained unchanged over the course of the study (Table 4).

\section{Discussion}

In the present study, after four weeks of treatment with ibuprofen SR in combination with standard medical care, patients suffering from chronic and mostly moderate-tosevere osteoarthritic pain reported significant improvements in day and night pain, reduced symptom severity of joint tenderness/stiffness, reduced duration of morning stiffness, and increased ability to carry out normal activities. These observations are consistent with studies that demonstrate the effectiveness of ibuprofen SR in relieving day and night pain in European and North American populations. ${ }^{13,15}$ To the authors' knowledge, the present study is the largest study conducted in a mixed Caucasian and African real-life general medical practice population in a developing country.

A large body of evidence exists regarding the effectiveness and tolerability of ibuprofen treatment in the management of pain and other symptoms associated with osteoarthritis. ${ }^{3,6,10,14,29}$

The Osteoarthritis Research Society International (OARSI) recommends NSAIDs for the management of knee and hip osteoarthritis in symptomatic patients who have both pain and inflammation. ${ }^{30}$ Ibuprofen has been shown to have comparable or superior efficacy when compared with other NSAIDs such as piroxicam and naproxen, and other analgesics such as paracetamol. ${ }^{29} \mathrm{As}$ a result, and in combination with a good safety and tolerability profile, ibuprofen is one of the most frequently prescribed NSAIDs. ${ }^{29,31}$

Studies also suggest that ibuprofen SR may be more effective than conventional-release ibuprofen in this condition. ${ }^{14,20}$ In a study in 578 United Kingdom primary care patients with osteoarthritis or rheumatoid arthritis, ibuprofen SR significantly improved day and night pain compared with conventional-release ibuprofen at 4 weeks. ${ }^{14}$ Patient opinion and investigator assessment of the clinical condition were also found to be superior with ibuprofen SR compared with conventional-release ibuprofen. ${ }^{14}$ In another study of 150 hospital outpatients with osteoarthritis of the knee, day and night pain was reduced after 4 weeks of treatment with ibuprofen SR; although, in this study, the efficacy was found to be similar to that seen in patients given conventionalrelease ibuprofen. ${ }^{19}$

A number of comparative trials with other NSAIDs have been conducted. An investigator-blind study of 61 patients with painful osteoarthritis of major joints attending rheumatology clinics in Switzerland randomly allocated the patients to either ibuprofen SR or diclofenac. ${ }^{16}$ The study found that the investigator's opinion of the clinical condition of their patients (the primary measure of efficacy) was significantly better for those treated with ibuprofen SR versus diclofenac. In a 4-week study of 59 elderly patients with osteoarthritis randomly allocated to either ibuprofen SR or piroxicam, improvements from baseline in joint restriction and pain scores were observed for both treatments. ${ }^{17}$ There was an indication of better 24-hour pain control and a trend towards fewer gastrointestinal AEs for patients treated with ibuprofen SR.

A common obstacle to the effective treatment of chronic conditions is low level of treatment compliance. This is particularly relevant for older populations, such as those affected by osteoarthritis, and for those experiencing problems related to polypharmacy, mobility, and cognitive function. A study has shown that only around $50 \%$ of patients with chronic conditions adhere to treatment, regardless of the disease, treatment, or age. ${ }^{32}$ In a small study of 156 patients with osteoarthritis, $44 \%$ of the patients reported being noncompliant as assessed by one of three behaviors: forgetting to take their medication; being careless about taking their medication; or stopping their medication when they felt better. ${ }^{33}$

Table 4 Vital sign data for number of patients assessed at each time point

\begin{tabular}{|c|c|c|c|c|}
\hline & Baseline & Week 2 & Week 4 & Follow up \\
\hline & 329 & 268 & 248 & 198 \\
\hline Systolic BP (mmHg) & $127.6( \pm 10.8)$ & $128.8( \pm 9.7)$ & $127.9( \pm 9.5)$ & $127.0( \pm 8.8)$ \\
\hline Patients with change from baseline in systolic & & $49(9.5)$ & $54(10.4)$ & $29(5.6)$ \\
\hline \multicolumn{5}{|l|}{$\mathrm{BP}$ of $\geq 5 \mathrm{mmHg}, \mathrm{n}(\%)$} \\
\hline Diastolic BP (mmHg) & $82.4( \pm 7.3)$ & $83.6( \pm 6.2)$ & $83.4( \pm 5.6)$ & $82.6( \pm 5.1)$ \\
\hline Patients with change from baseline in diastolic & & $54(10.4)$ & $48(9.3)$ & $20(3.9)$ \\
\hline \multicolumn{5}{|l|}{$\mathrm{BP}$ of $\geq 5 \mathrm{mmHg}, \mathrm{n}(\%)$} \\
\hline Heart rate (BPM) & $77.8( \pm 7.4)$ & 77.I $( \pm 7.7)$ & $76.0( \pm 6.5)$ & $76.2( \pm 6.4)$ \\
\hline $\begin{array}{l}\text { Patients with change from baseline in heart } \\
\text { rate of } \geq 5 \text { BPM, } n(\%)\end{array}$ & & $27(5.2)$ & $24(4.6)$ & $12(2.3)$ \\
\hline
\end{tabular}

Note: Data are mean ( \pm standard deviation) unless otherwise stated.

Abbreviations: BP, blood pressure; BPM, beats per minute. 
An inverse correlation between the prescribed frequency of dosing and compliance exists. ${ }^{15}$ In patients with rheumatoid arthritis, gout, and polymyalgia rheumatica, dosing frequency is a major factor affecting compliance to medication. ${ }^{34} \mathrm{In}$ a study of patients with hypertension, changing treatment from three times a day to once daily increased compliance from $59 \%$ to $84 \%{ }^{35}$ Therefore, reducing dosing frequency can significantly improve compliance.

In the present study, a high level of compliance with once-daily ibuprofen SR in a real-life clinical population was demonstrated. Maintenance of treatment compliance at this level in the medium-to-long term would increase overall effectiveness compared with lower rates of compliance observed in studies of chronic diseases using drugs with more frequent dosing regimens. This study supports the concept that selecting the lowest possible dosing frequency is a key action that clinicians can take in order to improve compliance and, consequently, the outcome of osteoarthritis treatment.

The safety and tolerability profile of NSAIDs is dependent on the population under investigation and the clinical setting, among other factors. A descriptive study in an Indian orthopedic outpatient department reported that $26 \%$ of adverse drug reactions reported over 3 months were due to NSAID use. ${ }^{36}$ In another study in an Italian hospital over 10 years, NSAIDs were found to be responsible for $55.2 \%$ of adverse drug reactions. ${ }^{37}$

In the present real-life observational study, ibuprofen SR was well tolerated by the majority of patients. Only $7.9 \%$ of the patients reported AEs. The reported AEs were similar to those observed in previous studies. ${ }^{14,19}$ It should be noted that the relatively short duration of this study (4 weeks) may be considered a limitation of the safety analysis as some AEs may be more likely to occur with longer treatment. However, following guidance from the US Food and Drug Administration that NSAIDs should be prescribed for the shortest time needed, 4 weeks appeared to be the most appropriate and ethical timeframe for evaluation. The most common events observed over this time were gastrointestinal-related AEs (particularly gastritis), which are well-characterized AEs for ibuprofen and other NSAIDs. Management approaches to minimize gastrointestinal AEs with ibuprofen and other NSAID treatments (particularly in elderly patients $\geq 75$ years of age where use is advised with caution) ${ }^{38}$ include coadministration of proton pump inhibitors. ${ }^{39}$ Interestingly, a recent review of NSAIDs in older patients revealed that $90 \%$ of all prescription NSAIDs are taken by patients $>65$ years of age. ${ }^{40}$ Guidelines for safe use are available but frequently not followed; physicians should exercise caution with regards to NSAID use in older fragile populations. ${ }^{40}$
All NSAIDs, in doses adequate to reduce inflammation and pain, can increase blood pressure in both normotensive and hypertensive individuals..$^{41,42}$ In addition, NSAIDs may reduce the effect of all antihypertensive drugs except calcium channel blockers. ${ }^{42}$ In this context, the data from this study are reassuring. Although the findings were based on a relatively small and selected population, there was no increase from baseline in blood pressure or heart rate in patients treated with ibuprofen SR.

The study was carried out in general medical practices of physicians with expertise and interest in the treatment of osteoarthritis, with the cost of treatment being paid by patients. Therefore, the patients in the study may not be representative of the wider population of adults suffering from osteoarthritis in Egypt, where nonprescribed purchase of NSAIDs is common, and self-treatment is widely practiced. Payment for treatment by patients meant that the financial status of patients had the potential to affect compliance, with poorer patients complying less fully. The high levels of reported compliance suggest that compliance was not adversely affected in this study. It can be speculated that payment by patients may even have contributed to the high compliance rates, perhaps because patients had financially invested in their treatment. Another limitation of the study is that more recent and advanced assessments such as WOMAC (Western Ontario and McMaster Universities Arthritis Index) or RAPID3 (Routine Assessment of Patient Index Data 3) were not performed, and patients were not assessed by location of osteoarthritis (ie, hip, hand, or knee). Furthermore, as this was an observational study in general medical practices, the majority of physicians did not routinely perform radiological assessments of affected joints and, therefore, this information is not available for assessment.

The general medical practice setting is, however, one of the strengths of the study. It was performed by physicians who regularly see and prescribe ibuprofen SR to patients with osteoarthritis as part of their routine clinical practice. An observational study likely provides a better idea of how treatments may affect subjects in their natural surroundings compared with randomized clinical trials that use highly selective patient populations and levels of care that are unrealistic in standard clinical practice.

This study provides useful additional insights into the role of ibuprofen SR in treating osteoarthritis in clinical practice. In particular, it presents data from a large number of patients treated in routine clinical practice and records improvements in pain and symptoms comparable with previous studies. 
More importantly, the study provides data from a mixed African and Caucasian population (outside of the developed world); this population is under-represented in the clinical research for chronic conditions. It may have implications for other populations, particularly in countries throughout the Middle East with similar environmental, cultural, and dietary characteristics.

\section{Conclusion}

In conclusion, this large real-life study of patients with osteoarthritis in Egypt demonstrates that ibuprofen SR in combination with standard medical care significantly improves pain and symptom scores, and is associated with a significant increase in the proportion of patients who are able to carry out normal daily activities. Patient compliance was high and treatment was generally well tolerated. These findings, consistent with those from previous studies, showed that ibuprofen SR is an effective treatment for the management of pain in patients with osteoarthritis and provides a convenient once-daily dosing regimen that may increase patient compliance.

\section{Acknowledgments}

The authors would like to acknowledge other clinicians who collected data for this study: Dr Adel Adawy, Dr Mostafa Shoheb, Dr Karim Masood, Dr Amgad Bolis, Dr Ashraf Bolis, Dr Refaei Al Saied, Dr Mahammed Sami El Zahaar, Dr Shereen Khalil, Dr Khaled Emara, and Dr Mahmoud El Sebaei. Data and clinical study reports were managed by ClinTec International Pvt Ltd, and statistical analysis was carried out by Sristek Consulting Pvt Ltd funded by Abbott Egypt Limited. We thank Mark Pownall from inScience Communications, Springer Healthcare, who provided medical writing support funded by Abbott Egypt Limited.

\section{Disclosure}

The authors report no conflicts of interest in this work.

\section{References}

1. Chopra A, Abdel-Nasser A. Epidemiology of rheumatic musculoskeletal disorders in the developing world. Best Pract Res Clin Rheumatol. 2008;22(4):583-604.

2. World Bank: Egypt, Arab Rep [webpage on the Internet]. Washington, DC: The World Bank Group; 2011. Available from: http://data.worldbank org/country/egypt-arab-republic. Accessed July 20, 2012.

3. Osteoarthritis [webpage on the Internet]. Atlanta: Centers for Disease Control and Prevention; 2012. Available from: http://www.cdc.gov/ arthritis/basics/osteoarthritis.htm. Accessed June 19, 2012.

4. World Health Organization. Country Cooperation Strategy for WHO and Egypt 2010-2014. Geneva: World Health Organization; 2010. Available from: http://www.who.int/countryfocus/cooperation_strategy/ ccs_egy_en.pdf. Accessed March 17, 2014.
5. Gallelli L, Galasso O, Falcone D, et al. The effects of nonsteroidal antiinflammatory drugs on clinical outcomes, synovial fluid cytokine concentration and signal transduction pathways in knee osteoarthritis. A randomized open label trial. Osteoarthritis Cartilage. 2013;21(9): 1400-1408.

6. Adatia A, Rainsford KD, Kean WF. Osteoarthritis of the knee and hip. Part II: therapy with ibuprofen and a review of clinical trials. J Pharm Pharmacol. 2012;64(5):626-636.

7. Altman RD. Review of ibuprofen for osteoarthritis. Am J Med. 1984;77(1A):10-18.

8. Boardman PL, Nuki G, Hart FD. Ibuprofen in the treatment of rheumatoid arthritis and osteo-arthritis. Ann Rheum Dis. 1967;26(6): 560-561.

9. Boureau F, Schneid H, Zeghari N, Wall R, Bourgeois P. The IPSO study: ibuprofen, paracetamol study in osteoarthritis. A randomised comparative clinical study comparing the efficacy and safety of ibuprofen and paracetamol analgesic treatment of osteoarthritis of the knee or hip. Ann Rheum Dis. 2004;63(9):1028-1034.

10. Lewis JR. Evaluation of ibuprofen (Motrin). A new antirheumatic agent. JAMA. 1975;233(4):364-365.

11. Varadi G, Zhu Z, Blattler T, et al. Randomized clinical trial evaluating transdermal Ibuprofen for moderate to severe knee osteoarthritis. Pain Physician. 2013;16(6):E749-E762.

12. Gallelli L, Galasso O, Urzino A, et al. Characteristics and clinical implications of the pharmacokinetic profile of ibuprofen in patients with knee osteoarthritis. Clin Drug Investig. 2012;32(12): $827-833$.

13. Kendall MJ, Jubb R, Bird HA, et al. A pharmacokinetic comparison of ibuprofen sustained-release tablets given to young and elderly patients. J Clin Pharm Ther. 1990;15(1):35-40.

14. O’Connor TP, Anderson AM, Lennox B, Muldoon C. A novel sustained-release formulation of ibuprofen provides effective once-daily therapy in the treatment of rheumatoid arthritis and osteoarthritis. $\mathrm{BrJ}$ Clin Pract. 1993;47(1):10-13.

15. Claxton AJ, Cramer J, Pierce C. A systematic review of the associations between dose regimens and medication compliance. Clin Ther. 2001;23(8):1296-1310.

16. Baumgartner H, Schwarz HA, Blum W, et al. Ibuprofen and diclofenac sodium in the treatment of osteoarthritis: a comparative trial of two once-daily sustained-release NSAID formulations. Curr Med Res Opin. 1996;13(8):435-444.

17. Earl RT, Jenkins R, Munro AJ. A double-masked comparison of the effiacy of once-daily sustained-release ibuprofen and once-daily piroxicam for 24-hour control of arthralgia due to osteoarthritis in the elderly. Current Therapeutic Research. 1996;57(10):811-821.

18. Fernandes L, Jenkins R. Investigation into the duration of action of sustained-release ibuprofen in osteoarthritis and rheumatoid arthritis. Curr Med Res Opin. 1994;13(4):242-250.

19. Flavell Matts SG, Hazleman BL, Houben H, Dhondt E, Tebbs VM. Controlled study of once-daily, sustained-release ibuprofen in osteoarthritis. Curr Ther Res Clin Exp. 1993;53(4):394-400.

20. Adam W. [Experiences with $800 \mathrm{mg}$ ibuprofen retard in ambulatory patients with activated osteoarthrosis and extra-articular rheumatic manifestations]. Z Rheumatol. 1991;50 Suppl 1:69-76. German.

21. Bradley JD, Katz BP, Brandt KD. Severity of knee pain does not predict a better response to an antiinflammatory dose of ibuprofen than to analgesic therapy in patients with osteoarthritis. J Rheumatol. 2001;28(5): 1073-1076.

22. Muller-Fassbender H, Bach GL, Haase W, Rovati LC, Setnikar I. Glucosamine sulfate compared to ibuprofen in osteoarthritis of the knee. Osteoarthritis Cartilage. 1994;2(1):61-69.

23. Giansiracusa JE, Donaldson MS, Koonce ML, Lefton TE, Ruoff GE, Brooks CD. Ibuprofen in osteoarthritis. South Med J. 1977;70(1): 49-52.

24. Franchimont $P$, Houben H, Tebbs VM. A double blind study to compare a once daily dose of $1600 \mathrm{mg}$ sustained release ibuprofen with standard $400 \mathrm{mg}$ ibuprofen tablets given four times daily in patients with osteoarthritis of the knee. Scand J Rheumatol. 1990;Suppl 85:61. 
25. Blagbrough US, Daykin MM, Doherty M, Pattrick M, Shaw PN. Synovial fluid and plasma levels of extended release ibuprofen in osteoand rheumatoid arthritis. J Pharm Pharmacol. 1989; Supplement 41: $144 \mathrm{P}$.

26. Baumgartner H, Scrimshire JA, Tebbs VM. A single blind, parallel group, multiple dose study of the efficacy and tolerability of sustained release ibuprofen and sustained release diclofenac sodium in the treatment of osteoarthritis. Scand J Rheumatol. 1990;Suppl 85(61).

27. Dominick KL, Baker TA. Racial and ethnic differences in osteoarthritis: prevalence, outcomes, and medical care. Ethn Dis. 2004;14(4):558-566.

28. International Conference on Harmonisation of Technical Requirements for Registration of Pharmaceuticals for Human Use (ICH). Guideline for Good Clinical Practice E6(R1) 1996. Available from: http://www. ich.org/fileadmin/Public_Web_Site/ICH_Products/Guidelines/Efficacy/ E6_R1/Step4/E6_R1_Guideline.pdf. Accessed August 24, 2012.

29. Oliva F, Gallelli L. Ibuprofen pharmacology and its implications for musculoskeletal disorders. Funct Neurol. 2010;25(Suppl 3):1-19.

30. Zhang W, Moskowitz RW, Nuki G, et al. OARSI recommendations for the management of hip and knee osteoarthritis, Part II: OARSI evidence-based, expert consensus guidelines. Osteoarthritis Cartilage. 2008;16(2):137-162.

31. Paul AD, Chauhan CK. Study of usage pattern of nonsteroidal antiinflammatory drugs (NSAIDs) among different practice categories in Indian clinical setting. Eur J Clin Pharmacol. 2005;60(12):889-892.

32. Dunbar-Jacob J, Erlen JA, Schlenk EA, Ryan CM, Sereika SM, Doswell WM. Adherence in chronic disease. Annu Rev Nurs Res. 2000;18:48-90.

33. Dominick KL, Golightly YM, Bosworth HB. Racial differences in analgesic/anti-inflammatory medication adherence among patients with osteoarthritis. Ethn Dis. 2005;15(1):116-122.
34. de Klerk E, van der Heijde D, Landewe R, van der Tempel H, Urquhart J, van der Linden S. Patient compliance in rheumatoid arthritis, polymyalgia rheumatica, and gout. $J$ Rheumatol. 2003;30(1):44-54.

35. Eisen SA, Miller DK, Woodward RS, Spitznagel E, Przybeck TR. The effect of prescribed daily dose frequency on patient medication compliance. Arch Intern Med. 1990;150(9):1881-1884.

36. Gor AP, Saksena M. Adverse drug reactions of nonsteroidal anti-inflammatory drugs in orthopedic patients. J Pharmacol Pharmacother. 2011;2(1):26-29.

37. Gallelli L, Colosimo M, Pirritano D, et al. Retrospective evaluation of adverse drug reactions induced by nonsteroidal anti-inflammatory drugs. Clin Drug Investig. 2007;27(2):115-122.

38. American Geriatrics Society Panel on Pharmacological Management of Persistent Pain in Older Persons. Pharmacological management of persistent pain in older persons. J Am Geriatr Soc. 2009;57(8): 1331-1346.

39. Scheiman JM, Hindley CE. Strategies to optimize treatment with NSAIDs in patients at risk for gastrointestinal and cardiovascular adverse events. Clin Ther. 2010;32(4):667-677.

40. McCarberg BH. NSAIDs in the older patient: balancing benefits and harms. Pain Med. 2013;14 Suppl 1:S43-S44.

41. Warner TD, Mitchell JA. COX-2 selectivity alone does not define the cardiovascular risks associated with non-steroidal anti-inflammatory drugs. Lancet. 2008;371(9608):270-273.

42. White WB. Cardiovascular effects of the selective cyclooxygenase-2 inhibitors. Subcell Biochem. 2007;42:145-158.
Open Access Rheumatology Research and Reviews

\section{Publish your work in this journal}

Open Access Rheumatology Research and Reviews is an international, peer-reviewed, open access journal, publishing all aspects of clinical and experimental rheumatology in the clinic and laboratory including the following topics: Pathology, pathophysiology of rheumatological diseases; Investigation, treatment and management of rheumatological

\section{Dovepress}

diseases; Clinical trials and novel pharmacological approaches for the treatment of rheumatological disorders. The manuscript management system is completely online and includes a very quick and fair peerreview system, which is all easy to use. Visit http://www.dovepress.com/ testimonials.php to read real quotes from published authors. 